\title{
CANTAR EN GRIEGO Y COREOGRAFIAR UNA ODA DE PÍNDARO
}

\author{
NATALIA PALOMAR PÉREZ \\ Universitat de Barcelona \\ npalomar@ub.edu \\ ORCID: 0000-0002-4901-445X
}

\section{RESUMEN}

En el marco de una asignatura de literatura griega me decidí a dar presencia al elemento musical de la lírica antigua. Para ello propuse a los estudiantes un proyecto insólito, orientado a un aprendizaje experiencial: que presentaran como intérpretes alguna composición de poesía lírica de la manera que más pudiera aproximarse a su ejecución originaria. Dos de ellos se animaron a intentarlo con la Olímpica XIV de Píndaro, contando con mi colaboración para todas las fases: la lectura comprensiva del poema, la selección de una melodía adecuada, la creación de una coreografía significativa, la localización del entorno más evocador, los ensayos y también la paulatina incorporación de los demás estudiantes en el proyecto. Todo este proceso culminó con una presentación pública en el jardín de la facultad: cantamos la oda en griego, con acompañamiento de clarinete, avanzando en procesión con otro estudiante en el papel de atleta vencedor, hasta el estanque que representaba el santuario de las Gracias. Los asistentes tuvieron libertad para entrar en la procesión y en todo caso la siguieron atentamente y aplaudieron. El acto se filmó y está cuidadosamente editado con subtítulos en UBtv.

PALABRAS CLAVE: lírica coral, Píndaro, canto coral, coreografía, didáctica experiencial.

\section{SINGING IN GREEK AND CHOREOGRAPHING A PINDAR'S ODE}

\section{ABSTRACT}

In a recent course on Greek Literature I decided to incorporate the musical element of ancient lyric. Hence, I proposed an unusual project to the students, aiming at an experiential learning: to perform a lyric composition in the way that would most resemble its original performance. Two students dared to try it with Pindar's Olympian 14, counting on my collaboration for all phases: the comprehensive reading of the poem, the selection of an appropriate melody, the creation of a significant choreography, the location of the most evocative environment, the rehearsals, as well as the gradual incorporation of the other students into the project. All this process culminated in a public performance at the university garden: we sang the ode in Greek, with clarinet accompaniment, advancing in procession with another student in the role of victorious athlete, to the pond that represented the sanctuary of the Graces. Attendees were free to join the procession. Overall, they followed the event closely and applauded at the end. The performance was filmed and carefully edited with subtitles. It is available at the university TV channel UBtv.

KEYWORDS: choral lyrics, Pindar, choral singing, choreography, experiential didactics.

El curso 2017-2018 tuve la oportunidad de reencontrarme con los líricos griegos arcaicos de la manera que más estimulante me resulta: junto con un grupo de 
estudiantes que había escogido la correspondiente asignatura, Literatura grega III. Èpica i lírica. A mí me parecía fundamental que pudiéramos apreciar-todosla consistencia rítmica de estas composiciones, así que empecé por poemas sencillos con patrones rítmicos simples (jonios, coriambos), estimulando a los estudiantes a captar en cada caso cómo el ritmo se adecuaba al contenido y a la intención del poeta. También había que tener en cuenta que prácticamente todos estos poemas eran de hecho canciones. Se me ocurrió buscar en la red: encontré algunas versiones cantadas que me parecieron dignas y las llevé a clase. Así, escuchando una y otra vez algunas canciones de Anacreonte musicadas por Petros Tabouris y coreándolas en clase, es como empezó a asomar la dinámica genuina de la lírica arcaica: conforme el grupo se iba apropiando de la canción, mediante la sensación física de plenitud inherente a cantar, en el gusto de aprender la canción de puro repetirla, con la referencia a una situación concreta de banquete -sugerida por imágenes en la pantalla (fig. 1) y por algún buñuelo recién hecho...

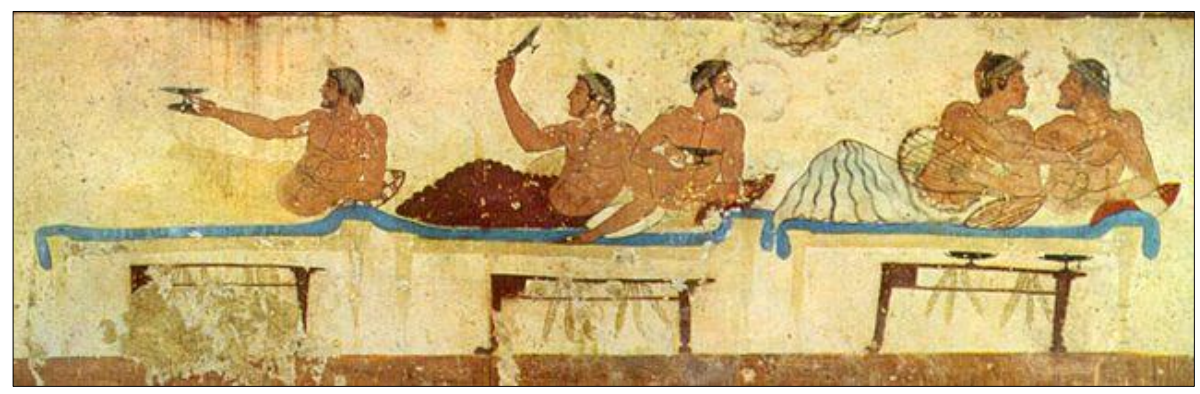

Fig. 1. Fresco de la Tumba del Nadador, 475 a. C., Museo de Paestum. Fuente: <scur.cat/HZPD9F> [consulta: 15 enero 2020].

En esta misma línea, ofrecí a los estudiantes la opción de escoger algún poema para presentarlo en clase de la manera que más pudiera aproximarse a la de su ejecución original -dentro de nuestras modestas posibilidades, por supuesto-. Si se trataba de una canción, cantándola; si había tenido acompañamiento instrumental, incorporando algún instrumento; si era una composición coral, formando un coro; etc.

No voy a disimular que la mayoría de los estudiantes prefirieron la otra opción más conservadora de hacer una reseña; y supongo que es comprensible, porque para ellos esta propuesta no tenía precedentes. Yo sí que había hecho un experimento similar el curso 2015-2016, en otra asignatura de literatura griega denominada Drama, con un grupo que estuvo de acuerdo en realizar un proyecto escénico a partir de Electra y Lisístrata. ${ }^{1}$ Y con el Grup de Teatre Clàssic también habíamos experimentado de qué manera podíamos componer figuras

\footnotetext{
${ }^{1}$ El resultado fue notable: una representación ante público de la facultad en el jardín y una filmación que editamos en forma de griegometraje: <www.ub.edu/ubtv/video/diplodipticodedicado-electra-sofocles-y-lisistrata-aristofanes-con-subtitulos> [consulta: 15 enero 2020].
} 
musicales y corales para unas Ranas y una Aulularia. ${ }^{2}$ De todos modos, también para mí esta vez resultaba arriesgado apuntar así (en el marco de una asignatura que impartía por primera vez y con estudiantes que no me conocían) a la presentación cantada en vivo de una pieza de lírica arcaica; pero me parecía irrenunciable. Además, era una oportunidad preciosa para continuar explorando las posibilidades de un aprendizaje experiencial de la literatura clásica. ${ }^{3}$

Por suerte, un par de estudiantes, Martina Escudero y Oriol Verdaguer, me dijeron que sí les parecía bien esa opción. Les propuse la lírica coral, dándoles a elegir el poeta que prefirieran, y Oriol se decantó por Píndaro según me dijo, "por curiosidad"-. ${ }^{4}$ Entonces les sugerí la Olímpica XIV, por ser breve, por resultar mucho más unitaria que otras y porque encontré una versión de Tabouris, cantada por un solista, que podía proporcionarnos la melodía. ${ }^{5}$ Más allá de estas cuestiones prácticas, se trata de una oda bellísima, que fue celebrada por Schiller y Goethe. ${ }^{6}$

\section{ENTRAR EN EL POEMA Y CANTARLO}

La primera fase de trabajo con Martina y Oriol consistió en leer el texto para comprender el registro literario de esta oda coral, que consiste en una doble invocación a las Gracias: en la primera estrofa, con una descripción de sus

2 Ranas (Aristófanes): <www.ub.edu/ubtv/video/griegometraje_2016/?s=1> (coro de las ranas, 13:00-15:45; coro festejando el triunfo de Esquilo, 37:40-39:36) [consulta: 15 enero 2020]. Aulularia (Plauto): <www.ub.edu/ubtv/video/aulularia-grup-de-teatre-classic/?s=1> (coro de duelo por la olla perdida, 42:04-43:19; coro del cortejo nupcial, 52:02-54:38) [consulta: 15 enero 2020].

${ }^{3}$ En el sentido que precisa Tolja, entrevistado por Puig (2016: 158-159): “Uno dei problemi principali dell'insegnamento è che quante più informazioni non verificabili esperienzialmente vengono date, tanto più si crea confusione e scollegamento tra attività mentale e corpo di chi si trova in un processo di apprendimento. Si crea cioè uno sbilanciamento tra la quantità di teoria effettivamente verificabile e l'esperienza che può realmente supportarla, sbilanciamento che porta al costituirsi di una mente disincarnata. Se immaginassi un'evoluzione del modello, rinuncerei quindi a una certa quantità di teoria a vantaggio dell'esperienza, in modo che il bilancio tra le due fosse più equilibrato".

$4 \mathrm{Me}$ parece un resorte totalmente respetable, pero conviene tener en cuenta lo que representaba -a efectos de lo que nos disponíamos a acometer- que estos alumnos no tuvieran idea previa sobre la obra de Píndaro y su complejidad poética.

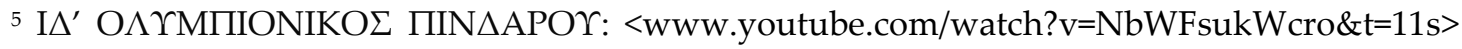
[consulta: 15 enero 2020]. Petros Tabouris (1967), músico y compositor, es reconocido por sus investigaciones sobre la historia de la música griega y aporta interesantes reconstrucciones de sus formas más antiguas. Otra ventaja de esta oda era que presenta metros eolios, $c f$. Snell y Maehler 1971: 57. En todo caso, a efectos rítmicos, me pareció que lo más sensato era atenernos a la composición de Tabouris (aunque no sigue las cantidades silábicas, sino que atiende preferentemente a los acentos, convirtiéndolos en intensivos), ya que el objetivo del proyecto era básicamente experiencial. Así pues, por una cuestión de prioridades y tiempo disponible, obviamos el debate sobre la métrica y la cuestión del "modo lidio", mencionado en la segunda estrofa; sobre todo ello, cf. especialmente Gentili 2013: 337-340 y Jiménez 2018: 68-69, así como las demás ediciones consultadas que constan en la bibliografía.

${ }^{6}$ Así lo apunta Alsina (1988: 231), el profesor que me transmitió la veneración por este poeta. 
competencias (destacando la de glorificar al padre Zeus); en la segunda, con referencias precisas al propio coro (que está cantando al atleta vencedor) y con otra invocación más: a Eco, para que lleve al padre difunto de este atleta niño la noticia de su gloria. ${ }^{7}$

Esta lectura del texto posibilitaba que en adelante identificáramos con precisión y agilidad a todos los personajes (divinos y humanos) y los diversos lugares mencionados por un nombre propio (topónimo o no), así como sus relaciones: Orcómeno, la 'opulenta' ciudad del vencedor (en Beocia), mencionada

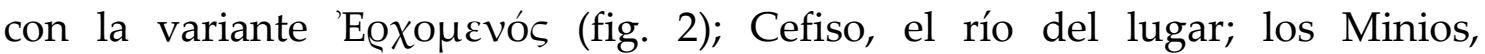
descendientes de Minias, el ancestro de la ciudad (también denominada aquí 'la Minia'); las Cárites o Gracias, con su culto local; Aglaya ('Espléndida'), Eufrósine ('Alegría') y Talía ('Floreciente'), sus respectivos nombres; Asópico, el niño vencedor; Cleodamo, su difunto padre; el padre Olímpico (Zeus); la mansión de

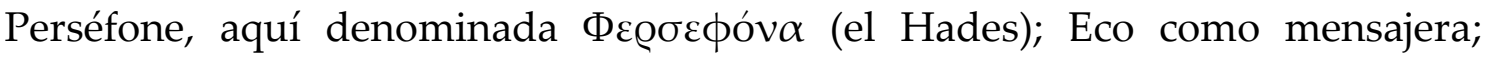
Olimpia, lugar de la competición, y Pisa, la ciudad a la que estaba vinculado ese célebre santuario.

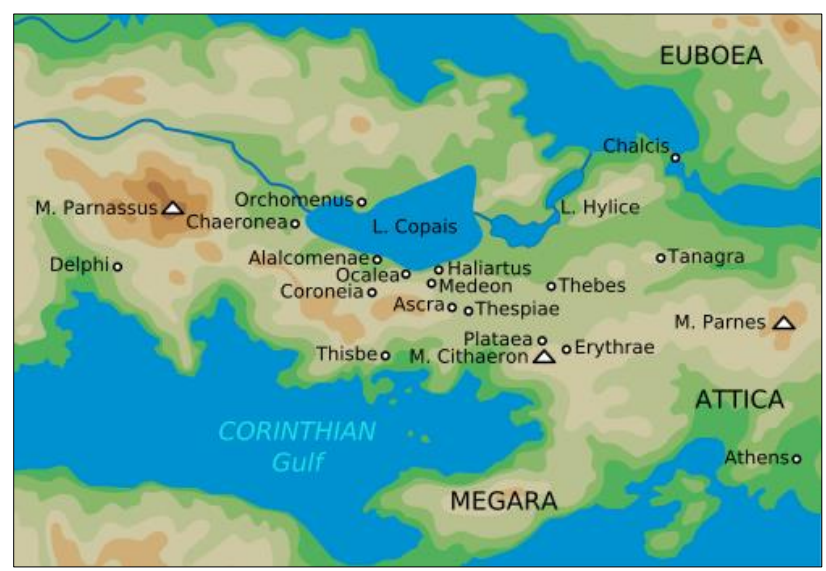

Fig. 2. Mapa de la antigua Beocia.

Fuente: <en.wikipedia.org/wiki/Boeotia> [consulta: 15 enero 2020].

Pero también era clave hacernos idea de ese personaje colectivo que se menciona con un nombre común, $\kappa \tilde{\omega} \mu \mathrm{os}$ : ese cortejo que cantando y bailando invoca a las Gracias para celebrar aquí el triunfo de este niño de aquí (de Orcómeno) que venció allí (en Olimpia).

En cuanto al tiempo, podíamos distinguir una doble referencia al presente: al ahora en que transcurre esta canción-invocación-celebración y al tiempo envolvente (valga la metáfora) en que se mantienen los usos estables en relación con las Gracias: su presencia cuando un hombre resulta excelente y cuando los dioses se recrean, su actividad en el cielo y sus vínculos con Apolo y Zeus. Por contraste, se hace alguna alusión al pasado remoto (cuando las Cárites obtuvieron estos lugares, cuando empezó el linaje de los Minias), otra al

\footnotetext{
7 Como es propio, en el desarrollo de nuestra lectura acudimos a los comentarios de esta oda, en particular al de Catenacci, Giannini y Lomiento en Gentili 2013: 613-621.
} 
momento reciente que fue la coronación de este atleta en Olimpia y otra a un hecho inminente: que Eco lleve la noticia de esta victoria al Hades.

En paralelo con nuestro trabajo de comprensión y asimilación del texto, íbamos escuchando y aprendiendo la melodía de Tabouris, naturalmente a base de cantar la oda. Cada uno la practicaba por su cuenta y en todos los encuentros de trabajo la cantábamos, buscando un tono que nos resultara cómodo. ${ }^{8}$

Por otra parte, compusimos una traducción interlineal que llevamos a clase, para compartir con los compañeros nuestros avances en la comprensión de la Olímpica. ${ }^{9}$ En esta edición diferenciamos los sintagmas del texto espaciándolos y disponemos la traducción de los mismos de tal manera que quede lo más paralela posible a ellos, si hace falta recurriendo a dos niveles y dos colores que permitan captar visualmente ciertos sintagmas cuyos elementos mantengo distanciados como en el original. ${ }^{10}$ El propósito es que esa disposición de los sintagmas en griego llegue a reconocerse como natural y significativa, sin dislocarla al traducir como solemos hacer. A estos efectos, lo que más ayuda es sin duda cantar la oda: en esa circunstancia, en lugar de aplicar la velocidad característica de la lectura silenciosa, nos instalamos en una cadencia, la de la canción, que al dar tiempo a cada palabra y a cada sintagma facilita nuestra orientación digamos sintáctica. En todo caso, así queda configurada esta edición:

Estrofa $\alpha$

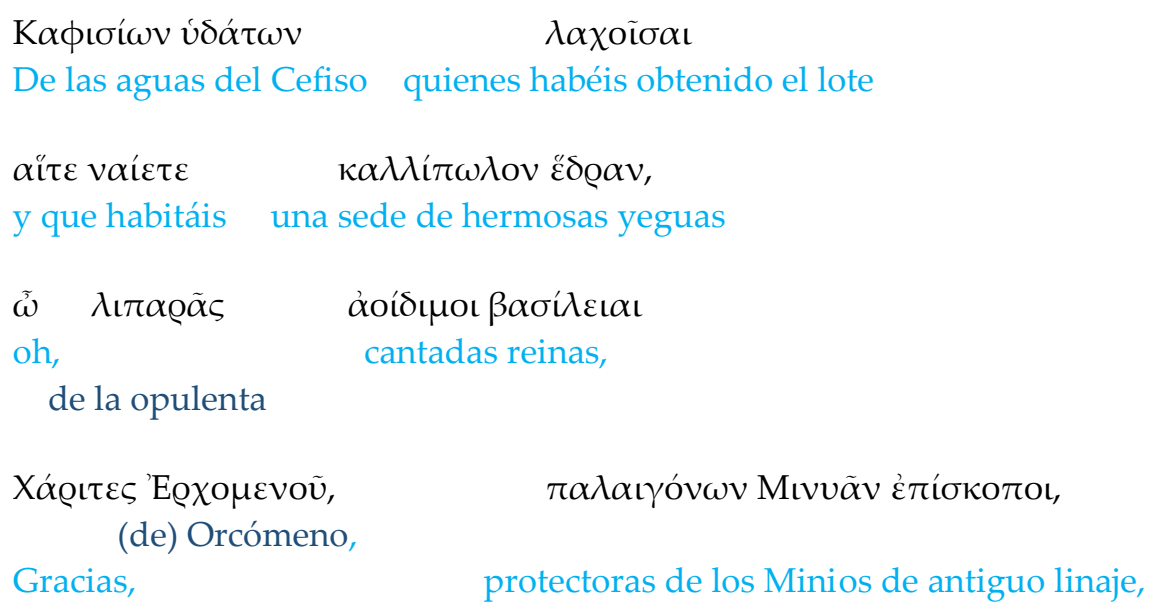

\footnotetext{
${ }^{8}$ Agradezco al profesor Ignasi Adiego que me explicara la construcción de esta melodía sobre la escala frigia, "partiendo de la nota si (si do re mi fa\# sol la si), en género diatónico", y que me facilitara su transcripción en la correspondiente partitura, así como interesantes comentarios: "la canción está armonizada con acordes claramente tonales, lo que distorsiona bastante el aire modal y más 'griego antiguo' que tendría si se cantara sin acompañamiento. Pero el empleo del modo frigio, enfatizando ciertos intervalos característicos (por ejemplo mi-do-si) crea un vínculo indudable con la música griega antigua".

9 Seguimos el texto de Pieraccioni (1965: 170-173), pero haciendo ciertos ajustes en la disposición de las líneas para que se correspondan con las frases melódicas de la versión de Tabouris.

${ }^{10}$ El criterio preferente en esta traducción es facilitar la lectura del original griego.
} 


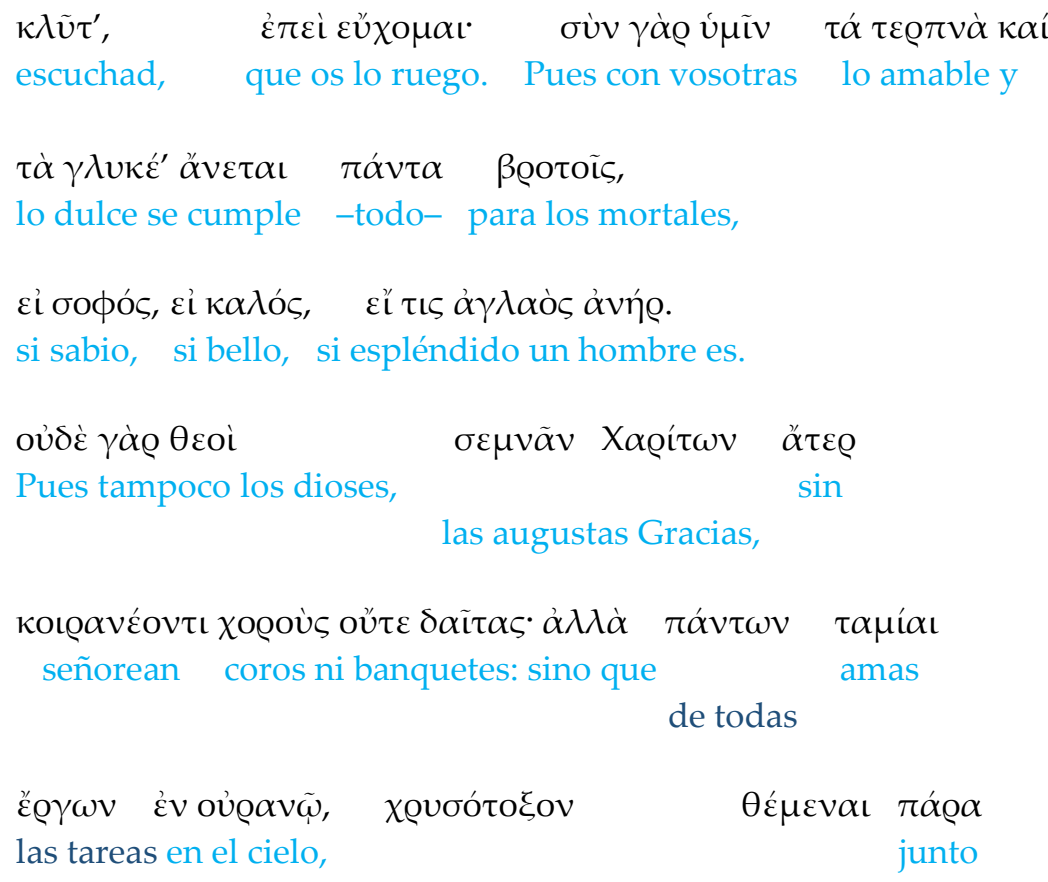

al Arcodeoro,

instalando

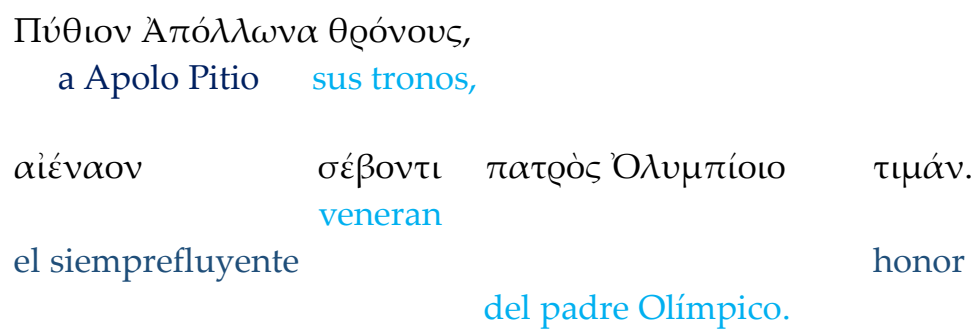

\section{Estrofa $\beta$}

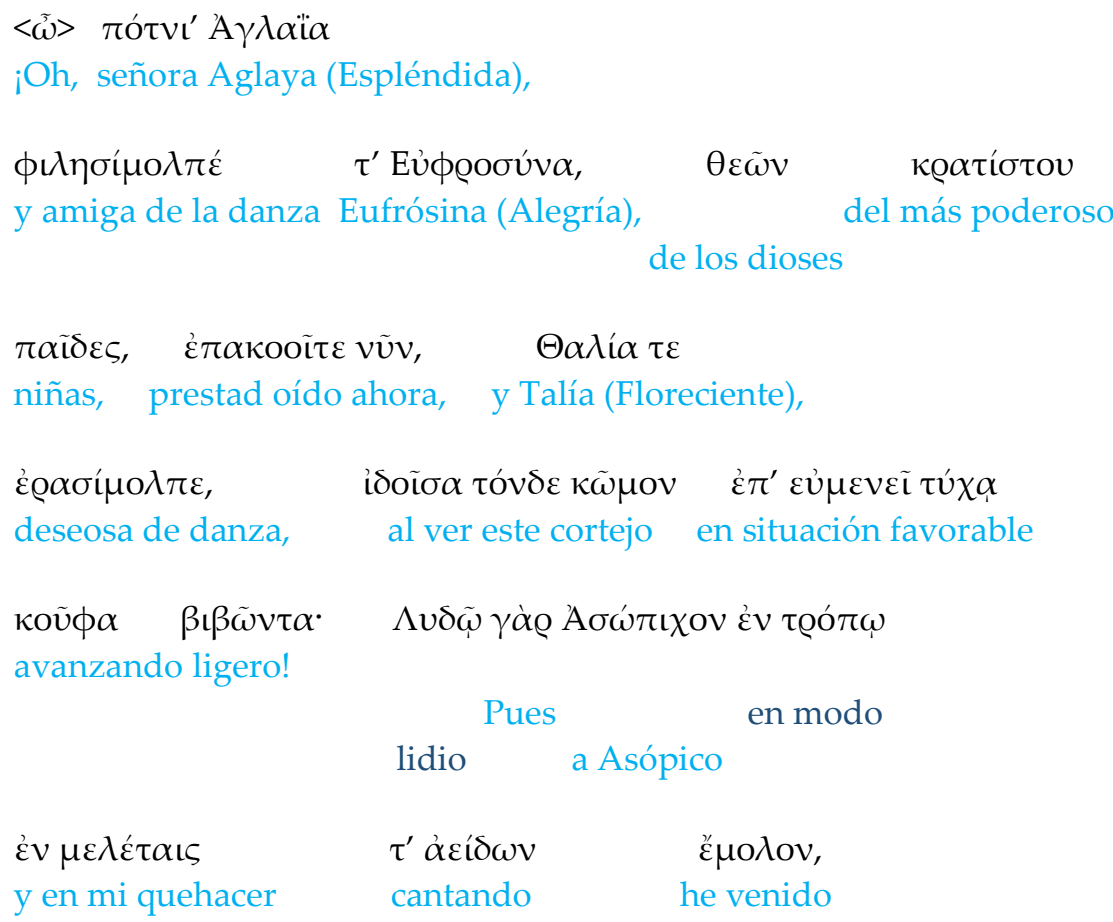




\begin{tabular}{|c|c|c|c|c|}
\hline 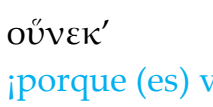 & \multicolumn{2}{|c|}{ 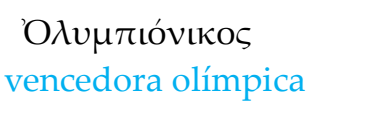 } & \multicolumn{2}{|c|}{$\begin{array}{c}\alpha \text { Mıvúcı } \alpha \\
\text { la (ciudad) Minia! }\end{array}$} \\
\hline $\begin{array}{l}\sigma \varepsilon \tilde{v} \varepsilon ̌ \kappa \alpha \tau \iota . \\
\text {-gracias a ti- }\end{array}$ & $\begin{array}{l}\mu \varepsilon \lambda \alpha \nu \tau \varepsilon \iota \chi \varepsilon ́ c \\
\text { de oscuros mu }\end{array}$ & viv & vó dó a la casa & \\
\hline \multicolumn{5}{|c|}{ 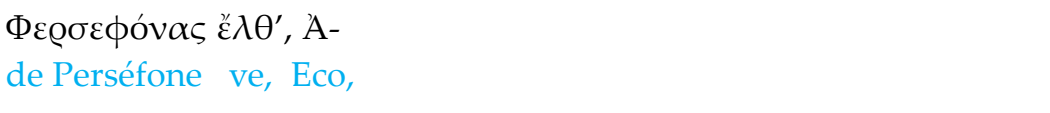 } \\
\hline 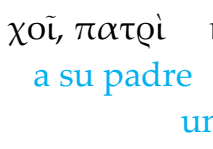 & 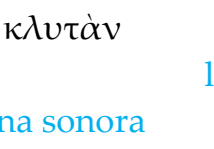 & $\begin{array}{l}\text { égoı } \sigma^{\prime} \\
\text { evando }\end{array}$ & $\begin{array}{l}\dot{\alpha} \gamma \gamma \varepsilon \lambda i ́ \alpha v, \\
\text { noticia, }\end{array}$ & \\
\hline 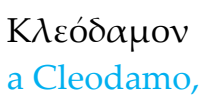 & 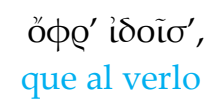 & $\begin{array}{l}\text { víòv } \\
\text { a su hijo }\end{array}$ & $\begin{array}{c}\text { عítins } \\
\text { menciones: }\end{array}$ & $\begin{array}{l}\text { ötı oi vé } \alpha v \\
\text { que su joven }\end{array}$ \\
\hline \multicolumn{5}{|c|}{ 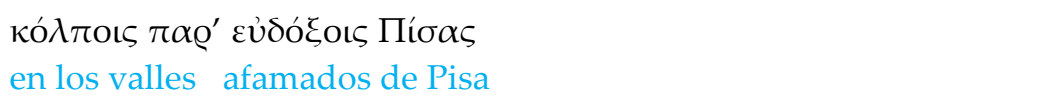 } \\
\hline 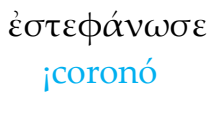 & 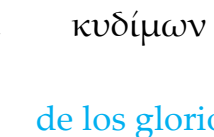 & $\begin{array}{l}\varepsilon \dot{\theta} \lambda \omega v \\
\text { os juegos }\end{array}$ & $\begin{array}{c}\pi \tau \varepsilon \varrho o \tilde{\sigma} \sigma \\
\text { con las alas }\end{array}$ & $\chi \alpha i ́ \tau \alpha \nu$. \\
\hline
\end{tabular}

\section{CONFIGURANDO LA PROCESIÓN}

Por mi parte, pronto empecé a esbozar un paso de marcha, marcando el compás de esa melodía mientras cantaba: eso sí, siempre cantando la Olímpica. La procesión me parecía el formato más adecuado, ya que en el texto se habla de

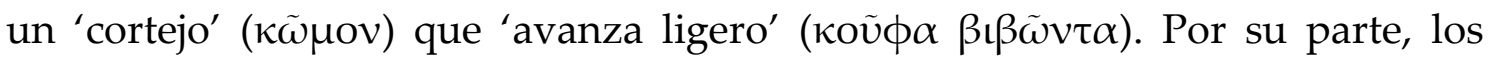
comentarios suponen la siguiente ceremonia ritual: el niño acude al santuario de las Gracias a ofrecerles su corona olímpica, en compañía de este coro (implicado en el culto de las diosas) que celebra su victoria y ante las gentes del lugar que acuden a recibirlo. ${ }^{11}$

Las partes de la melodía me orientaron para componer las figuras y marcar los contrastes en la coreografía. En un momento dado, la melodía parece que se frena, pues se pone a repetir una misma nota, la más grave, precisamente cuando las palabras plantean algo mediante negaciones: 'tampoco (oủdż) los

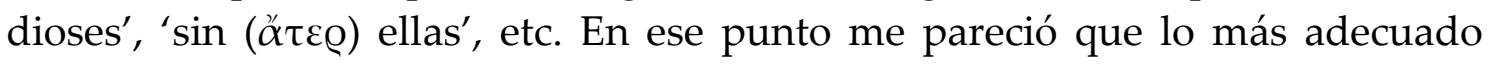
sería parar el avance y hacer un gesto de prohibición enfocado al público, que imaginaba a ambos lados: con el brazo extendido y el índice levantado, negar de izquierda a derecha, mirando a los ojos de los espectadores, y recoger luego el gesto (de derecha a izquierda) al mencionar lo que es competencia exclusiva de las Gracias, como sosteniéndolo en la palma de la mano. En cambio, la frase

\footnotetext{
${ }^{11}$ En esta descripción del festejo coinciden Gentili (2013: 339) y Pieraccioni (1965: 169).
} 
musical siguiente, al confirmar - por contraste- que las Gracias sí atienden tales funciones en el Olimpo, pedía otra figura que resolviera la traba anterior con un desenlace feliz. Un gesto expresivo podía ser levantar los brazos. Mi asesora de artes escénicas, María Mendoza, que se dedica a la danza creativa y se prestó a ensayar conmigo, me propuso además enlazar nuestras manos y girar (como en un árbol de mayo) hasta que volviera a aparecer el ritmo asociado a la marcha básica. $^{12}$

Luego, ensayando ya en el jardín con Martina y Oriol, encontramos el ajuste adecuado para hacer lo propio en la segunda estrofa: aquí el momento de la parada corresponde a la indicación que da el coro a Eco para que vaya a la mansión de Perséfone: vuelven a ser adecuadas las notas graves; y también la parada del coro, puesto que no es el coro, sino Eco, quien ha de movilizarse para llegar hasta allí. En este caso, para el primer sintagma 'gracias a ti' (de reconocimiento a Talía), el brazo se recoge en un gesto de reverencia, y para el segundo, 'hacia la morada de Perséfone', se extiende con el índice apuntando hacia ese lugar, el Hades, que en nuestro caso sugerían las escaleras descendentes y el pórtico del edificio, abajo al fondo. ${ }^{13}$

Hay que tener en cuenta que escogimos el jardín central porque su estanque principal, adonde vierten las aguas de ese otro redondo que queda escondido más arriba, resultaba altamente evocador de la imagen con que se

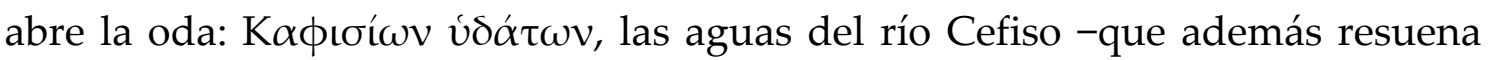

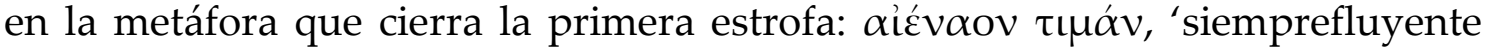
honor'. ${ }^{14}$ Decidimos que la procesión se dirigiera hacia allí, subiendo por las escaleras desde el nivel inferior: durante la primera estrofa, subir el primer tramo de escaleras y detenernos en el plano intermedio; durante la segunda, subir el segundo tramo y evolucionar por el plano más amplio que queda ante el estanque hasta concluir justo en el borde del mismo. Allí instalamos en un atril una reproducción (fotográfica) de un relieve arcaico que representa a las tres Gracias bailando, como señoras del lugar (fig. 3). ${ }^{15}$ El otro indicador espacial que activamos fue el levantar brazos y miradas para evocar el Olimpo.

12 María Mendoza (1989) es bailarina, intérprete y creadora, docente de danza, cuerpo y movimiento, cofundadora de Rius de Moviment. Le agradezco toda la formación que continuadamente me proporciona: con ella puedo adentrarme mejor en esta experimentación escénica orientada a la literatura grecolatina.

13 El visionado de la representación final puede ayudar a seguir estas explicaciones: $<$ www.ub.edu/ubtv/video/olimpica-natalia-palomar> [consulta: 15 enero 2020].

${ }^{14}$ Este primer plano, con su fondo frondoso -donde también viven las aguas de un tercer estanque con otro surtidor-, resultaba idóneo para evocar el santuario de las Gracias y convocarlas cantando este himno. En efecto, como explica Kirkwood (1982: 120), "They are associated with growth and bloom, with the flow of liquid, with gardens and plants, with the whole realm of nature included in the verb $\theta \dot{\alpha} \lambda \lambda \varepsilon\left\llcorner v^{\prime \prime}\right.$.

${ }^{15}$ El comentario de Catenacci, Giannini y Lomiento en Gentili 2013: 613 explica que en el templo antiguo de Orcómeno se veneraban tres piedras "che si narrava fossero cadute dal celo", 
Volviendo al asunto del canto, también en los ensayos vimos la ventaja de que Oriol se destacara como corifeo para decir él solo la frase que en la versión de Tabouris se canta a capella. Él mismo vio la oportunidad de levantar ambos brazos en este par de momentos de especial solemnidad: evocando a Apolo en la primera estrofa y preludiando la noticia de la victoria del hijo en la segunda. ${ }^{16}$ La frase final de la estrofa, como ya he dicho, vuelve con contundencia al esquema melódico básico y por tanto se reanuda el avance del cortejo cantor. En la segunda estrofa, repetimos esta frase última pero ya parados, pues hemos llegado al santuario de las Gracias y lo que hacemos es indicar al atleta los pasos que ha de dar para entregar la corona a las diosas.

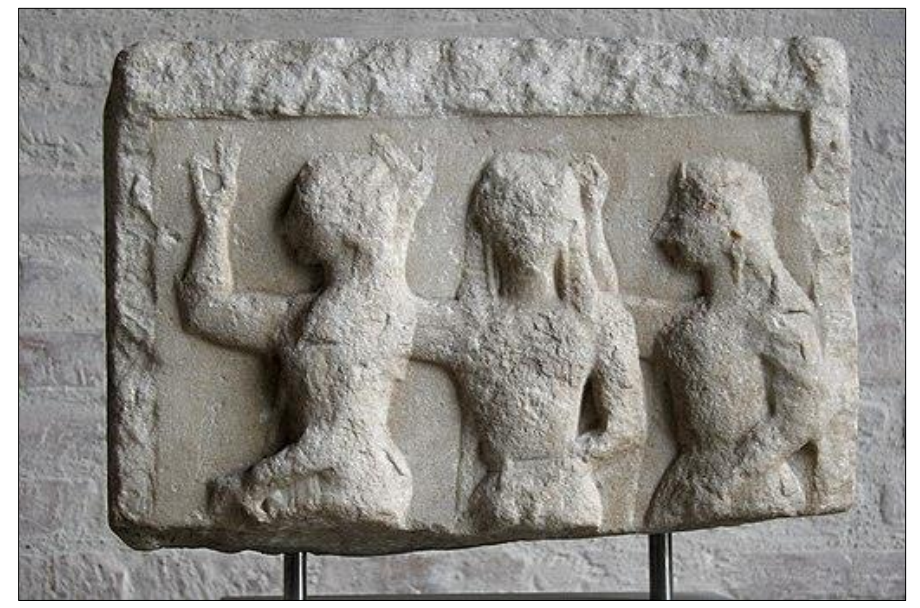

Fig. 3. Relieve de las Cárites, s. VI a. C., Glypothek München. Fuente: <scur.cat/4L5JXH> [consulta: 15 enero 2020].

\section{EXPANDIR EL EQUIPO Y OFRECER EL ESPECTÁCULO}

A todo esto, ¡habíamos incorporado un instrumento! Como al empezar la asignatura ya había preguntado a los estudiantes por sus conocimientos musicales, recordé que Àlex Aubet tocaba el clarinete y le propuse que se animara a acompañarnos; él aceptó generoso, aunque advirtiéndonos que llevaba tiempo sin practicar. Por tanto, a partir de un momento dado, se incorporó a los ensayos con su clarinete, haciendo algún ajuste en la melodía de Tabouris. ${ }^{17}$

En efecto, uno de los objetivos más o menos declarados de todo esto era implicar al resto de los compañeros. Así que los sorprendí en clase con alguna

que representaban a las Gracias, de manera que dar presencia a la piedra en esta figura también resultaba particularmente sugerente.

${ }^{16}$ En la no coincidencia melódica total de estas dos frases se plasma la relación métrica entre las dos estrofas: similitud pero no correspondencia exacta, como se explica en Gentili, $c f . n$. 5 .

${ }^{17} \mathrm{El}$ hecho de que el instrumento fuera un simple clarinete también demuestra que mi intención no era lograr una reconstrucción rigurosamente histórica, sino articular los elementos que integraban la lírica coral: poesía, canto, danza, música instrumental, presencias humanas y divinas, público, espacio ritual. 
actuación mía (seguramente ridícula), cantando y dando vueltas por el aula al compás del paso básico; a veces los recibía con el audio de Tabouris como música de fondo; también los animaba a asimilar cantando ese verso glorioso,

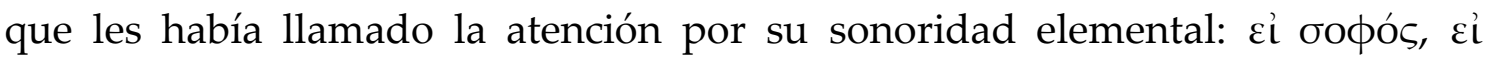

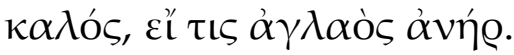

En un registro más académico, les planteaba cuestiones para que se imaginaran cómo podía haber sido aquella ceremonia, dibujando esquemas en la pizarra: si el $\kappa \tilde{\omega} \mu \mathrm{s}$ avanzaba cantando en honor del atleta y todos se dirigían al santuario de las Gracias, ¿quién iba delante?, ¿dónde iban los músicos?, ¿dónde estaban los espectadores?, ¿seguían la procesión o sólo la contemplaban al pasar?

Así también aportaron ideas para la coreografía conjunta en que al final se integraron, cada quién a su gusto, en un ensayo previo: algunos se animaron a entrar en la procesión marcando el paso, otros corearon (o no) la oda en posición de espectadores, con el texto que les habíamos proporcionado. A Mateu Portells le propusimos que representara al niño vencedor descalzándose (aunque nos olvidamos de pedirle que se afeitara para el día de la representación), y le confeccioné una corona de olivo, pues así eran las de Olimpia, realzada con un cordel dorado. Lucas Gonzalvo se prestó a grabar y a darle voz a Eco, diciendo y repitiendo el nombre de Asópico -un toque humorístico que se me ocurrió para explicitar más la idea poética de Píndaro en la película que tenía previsto editar-. ${ }^{18}$

El día de la actuación en público, que constituyó nuestra última sesión de clase, también se movieron con toda libertad, entrando o no en la procesión, los pocos amigos profesores y estudiantes a los que nos atrevimos a invitar -pues éramos conscientes de que se trataba de un intento muy elemental para una obra de tanta categoría-. Y resultó muy significativo que un grupo de estudiantes menores que estaban visitando la facultad respetaran el espectáculo y al final también aplaudieran. Animados por esta respuesta, les expliqué de qué se trataba e hicimos un bis, que ya siguieron más de cerca.

Así fue, pues: aquella espléndida mañana de mayo, sonó al aire libre por dos veces y en griego clásico la Olímpica XIV de Píndaro. ${ }^{19} \mathrm{Y}$ los participantes pudimos experimentar el sentido de cantar, nosotros, de viva voz y de una manera dinámica, la agilidad victoriosa del niño Asópico y la benévola presencia de las Gracias, en ese entorno tan sugerente que es nuestro jardín. Así ha quedado documentado en la filmación que realizamos del acto y su correspondiente edición (que incluye subtítulos), accesible en el canal de la

\footnotetext{
${ }^{18}$ Lucas tuvo la generosidad de grabar tanto el ensayo como las dos actuaciones que hicimos con público; aunque sin más instrumental que su móvil, sacó toda la ventaja posible de tal cámara en mano.

${ }^{19}$ En la versión cantada de Tabouris, la pronunciación es la del griego moderno.
} 
universidad UBtv. ${ }^{20}$ Ojalá todo ello nos estimule a continuar avanzando en esta aproximación experiencial a la lírica griega.

\section{BIBLIOGRAFÍA}

Alsina Clota, J. (1988), Píndaro. Epinicios, Barcelona, PPU.

GentiLI, B. (ed.) (2013), Le Olimpiche. Pindaro, Milán, Mondadori.

JiMÉNeZ COT, E. (2018), Comentario a las Olímpicas XIII y XIV de Píndaro, Barcelona, Universitat de Barcelona [trabajo de fin de máster].

KIRKWOOD, G. (1982), Selections from Pindar. Edited with an Introduction and Commentary, Chico (CA), Scholars Press.

PIERACCIONI, D. (1965), Antologia della lirica greca, Florencia, Sansoni.

SNELl, B. y MAEHLER, H. (eds.) (1971), Pindari carmina cum fragmentis, Leipzig, Teubner. TOLJA, J. y PUIG, T. (2016), Essere corpo, Milán, Tea.

20 PÍNDARO, Olímpica XIV - Coreografiada: <www.ub.edu/ubtv/video/olimpica-nataliapalomar> [consulta: 15 enero 2020]. 